AperTO - Archivio Istituzionale Open Access dell'Università di Torino

\title{
Social Mobility and Health in the Turin Longitudinal Study
}

\section{This is the author's manuscript}

Original Citation:

Availability:

This version is available http://hdl.handle.net/2318/4131

since

Terms of use:

Open Access

Anyone can freely access the full text of works made available as "Open Access". Works made available under a Creative Commons license can be used according to the terms and conditions of said license. Use of all other works requires consent of the right holder (author or publisher) if not exempted from copyright protection by the applicable law. 


\title{
Social mobility and health in the Turin longitudinal study is
}

\author{
Mario Cardano ${ }^{\mathrm{a}, *}$, Giuseppe Costa $^{\mathrm{b}}$, Moreno Demaria ${ }^{\mathrm{c}}$ \\ ${ }^{a}$ Department of Social Sciences, University of Turin, 50 Via S. Ottavio, Torino 10124, Italy \\ ${ }^{\mathrm{b}}$ Department of Public Health and Microbiology, University of Turin, Via Santena 5 bis Torino, 10126 Italy \\ ${ }^{\mathrm{c}}$ Environment Epidemiology Unit, Piedmont, Via Sabandia 164, Gugliasco (TO), 10095 Italy
}

\begin{abstract}
One of the most controversial explanations of class inequalities in health is the health selection hypothesis or drift hypothesis which suggests there is a casual link between the health status of individuals and their chances of social mobility, both inter- and intra-generational. This study tests this hypothesis, and tries to answer three related questions: (a) to what extent does health status influence the chances of intra-generational mobility of individuals? (b) what is the impact on health inequalities of the various kinds of social mobility (both mobility in the labour market and exit from employment) - do they increase or reduce inequalities? (c) to what extent does health-related intra-generational social mobility contribute to the production of health inequalities?

The data analysed in this paper were drawn from the records of the Turin Longitudinal Study, which was set up to monitor health inequality of the Turin population by combining census data, population registry records and medical records. Occupational mobility was observed during the decade 1981-1991. To evaluate the impact of the various processes of social mobility on health inequalities, mortality was observed over the period 1991-1999. The study population consists of men and women aged 25-49 at the beginning of mortality follow-up (1991), and registered as resident in Turin at both the 1981 and the 1991 censuses $(N=127,384)$. Health status was determined by observing hospital admission. For the purpose of the study healthy individuals were those with no hospital admissions during the period 1984-1986, while those admitted were classed as unhealthy. Social mobility in the labour market was measured via an interval data index of upward and downward movements on a scale of social desirability of occupations, designed for the Italian labour force via an empirical study carried out by de Lillo and Schizzerotto (La valutazione sociale delle occupazioni. Una scala di stratificazione occupazionale per l'Italia contemporanea, Il Mulino, Bologna, 1985). Movement out of the labour market was described by a discrete variable with four conditions: employed, unemployed, early retired and women returning from work to the housewife status. The relationship between health status and occupational mobility was analysed via analysis of variance and multinomial logistic regression. Health inequalities were measured by the ratio of standardised mortality rates in the unskilled working class and the upper middle class.

The study found a weak relationship between health status and occupational mobility chances. Decidedly stronger was the impact on occupational mobility of gender, education and "ethnicity" (being born in the South of Italy). The relationship between occupational mobility and health takes two different forms. Occupational mobility in the labour market decreases health inequalities; occupational mobility out of the labour market (early retirement, unemployment,
\end{abstract}

\footnotetext{
${ }^{2}$ The work is the result of a joint effort. Sections Data and methods and Results are written by Mario Cardano; and Sections Introduction and Discussion are written by Mario Cardano, Giuseppe Costa and Moreno Demaria.

*Corresponding author. Tel.: +39-011-670-26-94; fax: +39-011-670-26-12.

E-mail address: mario.cardano@unito.it (M. Cardano).
} 
housewife return) widens them. The maximum contribution health-related intra-generational social mobility can make towards health inequalities was estimated at about $13 \%$ for men.

(C) 2003 Elsevier Ltd. All rights reserved.

Keywords: Health selection; Intra-generational social mobility; Inequalities in health; Desirability of occupations; Turin longitudinal study; Italy

\section{Introduction}

Studies of the relationship between social class and health undertaken in Europe from the second half of the twentieth century almost all bring out two contradictory tendencies - a general rise in life expectancies, and the persistence - or sometimes even growth - of social inequalities (Marmot \& Wilkinson, 1999). The background to these patterns was wide-ranging demographic and epidemiological change. The nineteenth century saw sharply falling mortality, and especially infant mortality, throughout Europe. This general reduction in mortality (part of the "demographic transition") was paralleled by major change in the typical causes of death (the "epidemiological transition"). In spite of all this, social inequalities in health are remarkably persistent. This notable "sociological inertia" (Vågerö, 1991) has led to a number of research programmes which have tried to uncover the causal mechanisms - both biological and social-underlying the association between social status and health.

The present article considers one of the most controversial hypotheses, known in the epidemiological literature as the health selection hypothesis or drift hypothesis (Stern, 1983; West, 1991; Blane, Davey Smith, \& Bartley, 1993), which was first advanced in the 1930s (Perrot \& Collins, 1935; Lawrence, 1948; Illsley, 1955; Morris \& Heady, 1955; Perrot \& Sydenstriker, 1955; Meadows, 1961; Goldberg \& Morrison, 1963) and which argues that health status has a causal effect on individuals' chances of (inter- and intragenerational) social mobility. In other words, the selection hypothesis sees health as one of the factors responsible for "barriers to social mobility" (Giddens, 1973; Goldthorpe, 1980). The hypothesis takes on particular relevance-and sometimes becomes embroiled in ideological disputes - in the debate over social inequalities in health. Here it suggests that we need to reconsider what is the causal relationship between social class and health for it implies that not only is poor or good health a consequence of experiences associated with class location, but also itself a cause of those experiences thus to some extent of class position itself.

The selection hypothesis has usually been interpreted - not always without justification - as embodying an ideological attempt to deny the ethical and political importance of social inequalities in health (see, for example, the Black Report: Townsend \& Davidson, 1982). For if it is individuals' health which determines their social position, differences in the health status of the various classes cannot be seen as unjust, or rather cannot be seen as socially unjust, for the root cause is a cynical "lottery of nature", which gives some people sound and others poor health. This has led to the idea that the hypothesis which sees flows of social mobility as being affected by health is a form of "social Darwinism" (West, 1991), which portrays inequalities in health as part of a biological selection of the fittest for the posts of higher social responsibility. Researchers have thus been induced to document the lack of importance of genetic factors in the determination of social position (Kelleher, Cooper, \& Sadlier, 1990; Mascie-Taylor, 1990) and, more in general, to show how social mobility affected by health has a negligible effect on patterns of health inequalities (Wilkinson, 1986).

This interpretation of the selection hypothesis is not the only one possible, and perhaps not even the most plausible. There is no reason why we should see the hypothesis that social mobility may be affected by health as an absolute alternative to more widespread explanations regarding the origins of class inequalities in health which stress social causes. Processes of social mobility conditioned by health do not occur in a social vacuum (West, 1991). The hypothesis of selection for social positions on the basis of health can be seen, in our view, as a genuinely social process, moulded by (not necessarily appropriate) social representations of health and illness (Herzlich, 1973). This process takes shape in the context of social interaction, and is sometimes the result of conscious actions on the part of formal and informal agencies (Atkinson, 1981), and sometimes an unintended consequence of other actions. From this point of view, many selection processes based on health criteria could be seen as forms of social discrimination (West, 1991), and as forms of "social closure" (Parkin, 1979) which benefit this or that social group in competition with others. If this interpretation is correct, the selection hypothesis reinforces rather than denies the social dimension of health inequalities, although the causal link between social position and health changes from being linear to being circular. We believe that the health selection hypothesis is fully social, and it is in this spirit that we subject it to test. 
Our evaluation of the plausibility of the selection hypothesis, and of the size of any possible effect, draws on the Turin Longitudinal Study (TLS) Database, computerised records on mortality and morbidity of the population of Turin, including data going back to the 1971 census. In the present article we examine intragenerational (career) mobility-processes of mobility both within the labour market and out of it - so we look at change of occupation, loss of work, and early retirement. We intend to answer three questions: (a) to what extent does health status influence individuals' chances of intra-generational social mobility? (b) what impact do the various processes of social mobility in the labour market, plus exit from employment, have on health inequalities: do they exacerbate or moderate such inequalities? (c) to what extent does health-related intragenerational social mobility contribute to the production of health inequalities?

\section{Data and methods}

Data: The records of the TLS contain data on all individuals resident in Turin who were living in the city at one or more of the censuses of 1971, 1981 and 1991 (Costa, Cardano, \& Demaria, 1998; Cardano \& Costa, 1998). The records contain socio-demographic information taken from one or more censuses and combines itvia a procedure of record linkage (Costa \& Demaria, 1988)-with information from the city population register and health records. The records currently contain data on $1,958,901$ persons, of whom 527,970 were present at all three censuses. The portion of the records we will use is made up of people aged 25-49 at the time of the 1991 census, employed at the time of the 1981 census, and still resident in Turin in 1991 - a total of 127,384 individuals.

Operational definitions of the variables: The social status of individuals was defined via a combination of employment status and occupation as declared in the census. At the beginning of the period of observation, all subjects were by definition employed, so social status is based on occupation. At the end of the observation period (1991), those in employment were again classified by their occupation, while those who were not in work were classed according to employment status as unemployed, retired, or (for women) housewives. Occupations declared at the census were placed on a scale of the desirability of occupations introduced by de Lillo and Schizzerotto (1985). This scale contains 93 groups of occupations, which in turn contain a total of 590 individual occupations, seen as being representative of the world of work in Italy in the 1980s. All the occupations in any particular grouping have the same score of social desirability (the scale going from a theoretical 1 to a theoretical 100). At the bottom of the scale we find the occupations judged by de Lillo and Schizzerotto's interviewees to be least desirable occupations: for example, street cleaner $($ score $=9.87$ ) agricultural labourer (11.15), or domestic help (14.88). At the top of the scale we find the most desirable occupations such as entrepreneur (84.50), notary (85.67), or ambassador (90.20). Depending on their score on the social desirability scale, each of our individuals is allocated to a class, following a neo-Weberian model elaborated by de Lillo, Cobalti and Schizzerotto (de Lillo \& Schizzerotto, 1985; Cobalti \& Schizzerotto, 1994). In the version we use in this article, the model has six classes. Percentages in each class in the 25-49 resident population in 1981 and 1991 are given in Table 1.

This table provides background for interpreting results regarding the relationship between occupational mobility and health. In the period considered, and for the age-band we are studying (25-49), there was considerable change in Turin's occupational structure. There was considerable growth among both women and men in the percentages in upper middle class occupations such as the professions, managers and entrepreneurs. Vice versa, there was sharp contraction in the size of the skilled and unskilled working class: if we combine

Table 1

Social class of residents in Turin aged 25-49 in 1981 and 1991 (percentages)

\begin{tabular}{|c|c|c|c|c|}
\hline \multirow[t]{2}{*}{ Social class } & \multicolumn{2}{|l|}{ Men } & \multicolumn{2}{|l|}{ Women } \\
\hline & 1981 & 1991 & 1981 & 1991 \\
\hline Upper middle class & 8.8 & 16.6 & 3.6 & 8.0 \\
\hline White collar and semi-professional middle class & 25.3 & 25.5 & 45.4 & 51.9 \\
\hline Small employers (petite bourgeoisie) & 3.3 & 3.1 & 1.8 & 1.6 \\
\hline Self-employed (without employees) & 12.0 & 13.1 & 12.3 & 11.0 \\
\hline Skilled working class & 23.1 & 20.1 & 9.9 & 5.4 \\
\hline Unskilled working class & 27.5 & 21.6 & 26.9 & 22.1 \\
\hline$N$ & 168,050 & 148,002 & 100,341 & 106,589 \\
\hline
\end{tabular}


data for men and women, those in working class occupations formed $45 \%$ of the total in 1981 but only $36 \%$ in 1991 . These shifts - due partly to intra-generational mobility-have an important impact on the epidemiological profile of our population, so we need to take account of this in interpreting our results.

We measure occupational mobility within an individual's career between 1981 and 1991 by two indicesone metric, the other a categorical measure. Both use the difference between the social desirability scores of the occupation declared in 1981 and that declared in 1991. The metric index of occupational mobility (MIOM) measures movement on the scale of occupational desirability as a percentage reduction of the distance separating the individual in question from the top of the scale (if the mobility is upward) or from the bottom of the scale (if the mobility is downward). MIOM can vary from -100 (maximum possible downward mobility) to +100 (maximum possible upward mobility). Procedures used for calculating the index are given in the Appendix.

The categorical index of occupational mobility (CIOM) is calculated on the basis of the metric index, and classes people as stable (immobile) when MIOM is zero, upward when MIOM is greater than zero, and downward when it is less than zero.

Alongside mobility from one occupation to another we consider movement out of work. So we consider shifts from work to unemployment, to early retirement, and (for women only) to being a housewife. In the analyses we carry out on the whole population (men and women combined), this shift to housewife statusmaternity leave excluded - will be interpreted as discouragement, and seen as equivalent to losing work (an interpretation we admit will not always be valid).

Health status is defined by interpreting hospital admission as a sign of poor health. Individuals not admitted to hospital in the middle of the period of observation (1984-86) are considered healthy, those admitted, for any illness or accident, are considered as being in poor health. For women admissions for maternity are excluded. Use of hospital admission as an indicator of health obviously has its limits. This operational definition of health (the only one available for the population under study) in fact attributes the same state of poor health to individuals hospitalised for minor ailments and those admitted for major problems, which could affect the ability to work. In addition, use of the hospitalisation indicator means that our definition of poor health is influenced by factors like the propensity of individuals to resort to hospital treatment and the result of the negotiation between patients who want (or do not want) to be admitted and medical staff responsible for deciding admission. On the whole, it is reasonable to hypothesise that our operational definition overestimates the health problems in the population under study. However, the results of a preliminary analysis (Costa, Cardano, \& Demaria, 1998) lead us to think that the solution adopted is adequate. ${ }^{1}$

In order to have some control over the order in time of the events we believe may be related (hospital admission and occupational mobility), we attribute ill or healthy status only after introducing a series of conditions. These are summarised in Fig. 1.

Individuals selected for the study had to meet two conditions: they could not have been admitted to hospital (except for birth) in the period following declaration of occupation in the 1981 census. This condition is intended to ensure that we take into account only persons who are in good health as defined at the beginning of our period of observation of occupational mobility, i.e. October 1981. The second condition (that persons should be employed at the time when the period of hospital observation ends in 1986) aims to exclude individuals for whom it is problematic to determine the priority in time of the two phenomena we are concerned with-poor health and occupational mobility.

We have compared the effect of health status on occupational mobility to that of processes of discrimination or "social closure" (Parkin, 1979), linked to gender

\footnotetext{
${ }^{1}$ The preliminary analysis (Costa, Cardano, \& Demaria, 1998), undertaken on the adult (30-64) male population, examined the risk of being expelled from the labour market via unemployment or retirement for those admitted for severe as against minor illnesses. Reasons for hospitalisation were divided into two broad categories plus a middle residual category. In the first category, defined as "definitely incapacitating diseases", were included heart attacks 410-414, acute cerebro-vascular diseases 430-434, diabetes 250, glaucoma 365 , and the following cancers with a favourable prognosis: cancer of the large intestine 153-154, of the bladder 188, of the testicle 186, of the thyroid 193, of the breast 174, Hodgkin's disease 2001. In the second category, defined "definitely not incapacitating diseases", were included appendicitis 540-543, gastritis 535, calculi 592-594, haemorrhoids 455 , bile stones 574-575. These two categories between them accounted for a little over $20 \%$ of all admissions. All other causes of admission were placed in a third residual category. The risk of labour market exit was then compared for the three categories and it was found that both with regards to unemployment and retirement, the risk for those in the third, residual category was closer to that incurred by those in the first, "definitely incapacitating" than to the second "non-incapacitating" category. To be precise, the relative risk of unemployment was 1.34 for patients admitted for definitely incapacitating illnesses, 1.01 for those suffering from "not incapacitating" illnesses, and 1.25 for those with illnesses in the broad and uncertain residual category. With regard to exit to retirement, the risk was 1.11 for those in the first ("incapacitating") category, 1.03 for those in the second (non-incapacitating) class, and 1.08 for those in the third undefined group. These relative risks, together with the fact that the third, residual category covers nearly $80 \%$ of all admissions, comforts us in thinking that our operational definition of health is not too badly flawed (as well as being the only one which could give us statistically robust results).
} 


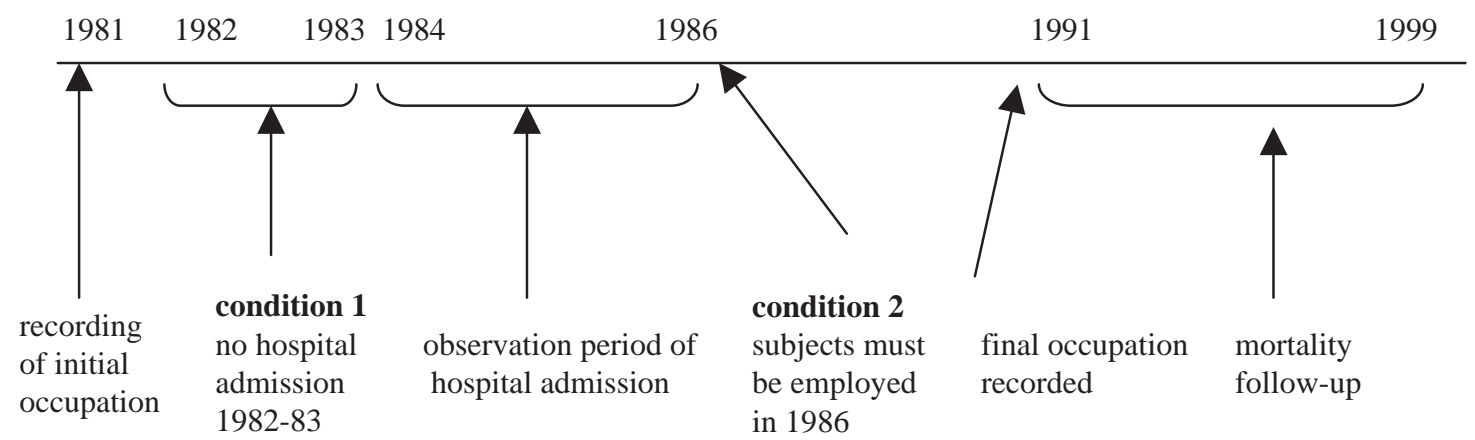

Fig. 1. Constraints adopted when attributing ill or healthy status to individuals studied.

or to class origins, or also - in some circumstances - to geographical origins. This is the case in Turin, where labour migration from the South of Italy in the 1950s and 1960s produced a major social division which still has effects on Turin's structure of inequalities (partly because the great majority of immigrants were working class, partly because there was a specific "quasi-ethnic" effect), for in Turin coming from the South is linked to major processes of social closure (Baldissera, 1984). In addition, we have considered the effects of educational credentials. Estimates of the effects of these factors were obtained via a set of dummy variables which represent the status of each individual with regard to each of the factors considered. Thus we have a variable WOMAN, which is 1 if the subject is a woman and 0 if a man. MOTHER is 1 if the woman in question is mother of at least one child who in 1991 was 14 or less. SOUTHERNER equals 1 if the subject was born in the South of Italy, LOW EDUCATION is 1 if the subject has schooling which is equal to, or less than, legally compulsory schooling ( 8 years). These variables were then used to construct first-, second- and third-order interaction terms, including the dummy variable for the health of an individual.

Statistical models and measures: To investigate the relationship between state of health and mobility, we undertook an analysis of variance (for the MIOM measure) and a multinomial logistic regression (for the CIOM classification). In the analysis of variance, age and the 1981 score on the social desirability scale of occupations were the control variables. The size of social inequalities in health was calculated by taking the ratio between standardised rates of mortality in the unskilled manual class and the upper middle class, and the number of deaths which could be attributed to this, using the upper middle class as the reference category. All mortality statistics were controlled for age and broad region of birth (five regions were considered: Piedmont, rest of North-West, North East, Centre, South and Islands).
Table 2

Occupational mobility within the labour market and exit from the labour market in Turin between 1981 and 1991

\begin{tabular}{lc}
\hline Occupational mobility and labour market exit & \% \\
\hline Stable & 27.3 \\
Upwardly mobile & 43.2 \\
Downwardly mobile & 24.1 \\
Lost work & 2.4 \\
Becomes housewife (women only) & 1.7 \\
Early retirement & 1.3 \\
Study population & 127,384 \\
\hline
\end{tabular}

Men and women, aged 25-49, living in Turin at 1981 and 1991 census (percentages).

\section{Results}

Table 2 summarises the kinds of occupational mobility which our population has experienced. The modal experience has been that of upward mobilitynot surprising given the transformation in the occupational structure in the 1980s, which was shown in Table 1. It is also worth noting that almost three-quarters of the total saw some change in their position vis-à-vis the labour market (either upward or downward occupational mobility or movement out of the labour market altogether) between 1981 and 1991. This reflects the sensitivity of our measure of mobility compared with those used in other studies (cf. van de Mheen, Stronnks, Schrijvers, \& Mackenbach, 1999), which have tended to find the proportions of mobile to immobile virtually inverted.

\section{To what extent does health status influence individuals' chances of occupational mobility?}

Table 3 focuses on occupational mobility within the labour market, i.e. on those individuals who were 
employed in both 1981 and 1991. The table gives the parameters of the analysis of variance we undertook using the MIOM as the dependent variable. The two control variables (age and social desirability of the 1981 occupation) are also included. Age is expressed in years. We standardised the score on the social desirability scale - transforming the mean into zero and making the standard deviation equal to 1 -in order to facilitate comparison between this parameter and the other variables in the model, which are all dummy variables.

The table shows a relationship in the direction predicted between state of health (as reflected in hospital admission) and chances of occupational mobility. Poor health in fact tends to push people towards lower-status occupations. The effect is however modest-a reduction of a little under one and a half per cent in the distance between the initial position and the bottom of the social

Table 3

Occupational mobility and discriminating factors

\begin{tabular}{lrc}
\hline Parameters & Estimate & $\operatorname{Pr}>|t|$ \\
\hline INTERCEPT & 9.97 & $<0.0001$ \\
AGE & 0.25 & $<0.0001$ \\
SOCIAL DESIRABILITY OF & -12.60 & $<0.0001$ \\
INITIAL (1981) OCCUPATION & & \\
WOMAN & -4.58 & $<0.0001$ \\
LOW EDUCATION & -19.59 & $<0.0001$ \\
SOUTHERNER & -8.01 & $<0.0001$ \\
HOSPITALIZED 1984-1986 & -1.42 & $<0.0001$
\end{tabular}

$N=109,413$

$F$ test $=2494 \operatorname{Pr}>F<0.0001$

$R^{2}=0.14$

Analysis of variance. Dependent variable: MIOM, metric index of occupational mobility. Population: men and women aged 25-49 at the 1991 census, employed in 1981 and in 1991. desirability scale (see Appendix). In relation to the changes in the occupational structure referred to earlier (Table 1), it therefore seems reasonable to see poor health as more than anything a barrier to chances of upward mobility (cf. Table 2). Chances of upward occupational mobility are however much more limited by low education $(-19.59)$, by geographical origins $(-8.01)$, and by gender $(-5.58)$. To sum up, we may say that the analysis indicates the existence of a process of discrimination based on health, but that the size of this effect is much smaller than that due to the social closure associated with social origins or gender.

Table 4 shows the impact of the mobility factors considered for men and women separately. In this table we express occupational mobility in terms of the categorical index CIOM, which has three states - stable, upwardly mobile and downwardly mobile. The effects on mobility of the various factors considered were assessed via a multinomial logistic regression, taking "stable" as the reference category. The table gives odds ratios and confidence intervals.

Low educational qualifications reduce the chances of upward mobility and increase the chances of downward mobility for both men and women, but the effect is larger for men. Being born in the South has an effect on chances of upward mobility which is similar for both men and women, but its effect on increasing the likelihood of downward mobility is small and only holds for men. The effect of hospitalisation, in both genders, is small and not statistically significant. For women interaction between hospital admission, being born in the South, and being a mother increases the likelihood of downward mobility (odds ratio 1.74; confidence interval 1.29-2.34).

Tables 5-7 focus on exit from employment in the forms of unemployment, early retirement and (for women) becoming a housewife. The model estimated

Table 4

Determinants of mobility within the labour market

\begin{tabular}{|c|c|c|c|c|}
\hline \multirow[t]{2}{*}{ Independent variables } & \multicolumn{2}{|c|}{ Upward mobility } & \multicolumn{2}{|c|}{ Downward mobility } \\
\hline & Men & Women & Men & Women \\
\hline \multicolumn{5}{|l|}{ Low education } \\
\hline Odds ratios & 0.31 & 0.49 & 1.98 & 1.43 \\
\hline Confidence intervals & $0.29-0.33$ & $0.46-0.53$ & $1.87-2.10$ & $1.33-1.54$ \\
\hline \multicolumn{5}{|l|}{ Southerner } \\
\hline Odds ratios & 0.70 & 0.61 & 1.07 & 0.95 \\
\hline Confidence intervals & $0.68-0.73$ & $0.53-0.67$ & $1.03-1.12$ & $0.87-1.04$ \\
\hline \multicolumn{5}{|c|}{ Hospitalisation 1984-1986 } \\
\hline Odds ratios & 0.94 & 0.94 & 1.04 & 0.98 \\
\hline Confidence intervals & $0.89-1.01$ & $0.87-1.02$ & $0.97-1.12$ & $0.90-1.06$ \\
\hline
\end{tabular}

Men and women aged 25-49 at the 1991 census and employed in 1981 and 1991; odds ratios and confidence intervals (reference category: stable). 
Table 5

Determinants of mobility in the labour market and of exit from employment

\begin{tabular}{|c|c|c|c|c|}
\hline & Upward mobility & $\begin{array}{l}\text { Downward } \\
\text { mobility }\end{array}$ & $\begin{array}{l}\text { Unemployment or } \\
\text { discouraged (housewife) }\end{array}$ & Early retirement \\
\hline \multicolumn{5}{|l|}{ Woman } \\
\hline Odds ratios & 0.66 & 0.88 & 2.79 & 3.74 \\
\hline Confidence intervals & $0.64-0.68$ & $0.85-0.91$ & $2.61-2.99$ & $3.32-4.20$ \\
\hline \multicolumn{5}{|l|}{ Low education } \\
\hline Odds ratios & 0.37 & 1.78 & 1.85 & 0.75 \\
\hline Confidence intervals & $0.35-0.38$ & $1.70-1.86$ & $1.69-2.03$ & $0.65-0.86$ \\
\hline \multicolumn{5}{|l|}{ Southerner } \\
\hline Odds ratios & 0.62 & 1.12 & 0.97 & 0.74 \\
\hline Confidence intervals & $0.60-0.64$ & $1.08-1.16$ & $0.90-1.03$ & $0.66-0.83$ \\
\hline \multicolumn{5}{|l|}{ Mother } \\
\hline Odds ratios & 0.95 & 1.04 & 1.16 & 0.96 \\
\hline Confidence intervals & $0.89-1.01$ & $0.97-1.10$ & $1.06-1.28$ & $0.83-1.11$ \\
\hline \multicolumn{5}{|c|}{ Hospitalisation 1984-1986 } \\
\hline Odds ratios & 0.95 & 1.04 & 1.08 & 1.46 \\
\hline Confidence intervals & $0.90-0.99$ & $0.98-1.09$ & $0.98-1.19$ & $1.25-1.69$ \\
\hline
\end{tabular}

Men and women aged 25-49 at the 1991 census, employed in 1981; odds ratios and confidence intervals (reference category: stable).

Table 6

Determinants of exit from employment

\begin{tabular}{|c|c|c|c|c|c|}
\hline \multirow[t]{2}{*}{ Independent variables } & \multicolumn{2}{|c|}{ Early retirement } & \multicolumn{2}{|c|}{ Unemployment } & \multirow{2}{*}{$\frac{\text { Discouraged }}{\text { Women (only) }}$} \\
\hline & Men & Women & Men & Women & \\
\hline \multicolumn{6}{|l|}{ Low education } \\
\hline Odds ratios & 0.93 & 0.74 & 1.95 & 1.97 & 1.87 \\
\hline Confidence intervals & $0.70-1.25$ & $0.63-0.87$ & $1.65-2.31$ & $1.65-2.33$ & $1.64-2.14$ \\
\hline \multicolumn{6}{|l|}{ Born in South } \\
\hline Odds ratios & 0.69 & 0.71 & 1.05 & 1.02 & 0.79 \\
\hline Confidence intervals & $0.56-0.85$ & $0.62-0.82$ & $0.94-1.17$ & $0.90-1.16$ & $0.71-0.88$ \\
\hline \multicolumn{6}{|c|}{ Hospitalisation 1984-1986 } \\
\hline Odds ratios & 1.48 & 1.43 & 1.20 & 0.85 & 1.11 \\
\hline Confidence intervals & $1.12-1.96$ & $1.19-1.71$ & $1.02-1.42$ & $0.70-1.03$ & $0.96-1.28$ \\
\hline \multicolumn{6}{|l|}{ Being a mother } \\
\hline Odds ratios & - & 0.99 & - & 0.98 & 1.29 \\
\hline Confidence intervals & & $0.85-1.15$ & & $0.84-1.15$ & $1.15-1.44$ \\
\hline
\end{tabular}

Men and women 25-49 at the census of 1991; odds ratios and confidence intervals (reference category: stable).

for the entire population (see Table 5) shows that it is gender (being a woman) which has the biggest impact on exit. The odds ratio here is 2.79 for losing one's job or becoming discouraged (we do not distinguish the two processes) and this rises to 3.74 for early retirement. The relevance of educational qualifications is confirmed, but its effects on exit from unemployment are uneven: it has a substantial positive effect on exit to unemployment, and a negative effect on exit to early retirement. Health status has a fair effect on exit towards early retirement, but a smaller one on exit towards unemployment. We saw earlier that social origin (as measured by being born in the South) was important for mobility within the labour market; however, it does not constitute an 
Table 7

Social mobility and inequalities in mortality

\begin{tabular}{llll}
\hline Men & & & \\
\hline Total & Stable & Mobile within the labour market & $\begin{array}{l}\text { Exited labour market through } \\
\text { unemployment or early retirement }\end{array}$ \\
\hline 1.72 & 2.47 & 1.53 & 3.41 \\
$1.35-2.19$ & $1.48-4.13$ & $1.17-2.01$ & $0.66-17.62$ \\
Women & & & \\
\hline Total & Stable & Mobile within the labour market & Left labour market through \\
& & & unemployment, becoming \\
housewife or early retirement
\end{tabular}

Ratio between standardised mortality rates 1991-1999 and confidence intervals of unskilled workers and those of upper middle class. Individuals aged 25-49 at 1991 census, according to their experience of occupational mobility.

important factor when we turn to exit from labour market. Its effect is almost nil on exit towards unemployment, and even makes early retirement less likely. Finally, we should mention the effects of being a mother. These effects vary for the different kinds of exit: with regard to leaving work for early retirement (and thus another income) the odds ratio is only 0.96 , while as for leaving work for unemployment or for becoming a housewife (and thus virtually no income) the odds ratio is 1.16 .

Similarities and differences between the two populations are shown in Table 6, where the impact of the factors considered so far are estimated separately for men and women.

The relationship between education and exit from employment follows similar patterns for both sexes. Low educational qualifications increase the likelihood of unemployment for men, as much as for women. For women, in addition, lack of education makes more likely the move towards becoming a housewife. Low education seems to protect against the probability of early retirement. The absence of any link between birth in the South and exit from employment emerges again (cf. Table 5). As for the effects of health, as measured by hospital admission, the effect is quite significant, and of similar size for both sexes, as a predictor of early retirement (odds ratio men: 1.48; women: 1.43). Hospitalisation's effect on exit through unemployment is different for men and women. It is almost nil for women, whereas for men it is slightly higher than the probability of having a mobility status of "stable". Among women, poor health increases the likelihood of becoming a housewife. In addition, this form of exit from employment (leaving employment for maternity leave is not counted) exceeds by almost $30 \%$ the probability of having a mobility status of "stable" for women with at least one child, who at the beginning of the observation period (1981) was at least 14.

\section{What impact do the various processes of social mobility} have on health inequalities?

Table 7 shows the effects, for men and for women, of various kinds of social mobility on inequalities in mortality. To be precise it gives the ratio between the standardised mortality rates of the class at the top of the hierarchy and that at the bottom-between the upper middle class and the unskilled working class. Social class is defined as that in 1991 for those who were in work at that date, and as that in 1981 for those who were not. Mortality was calculated separately for three subgroups - those who were classed as "stable" $(\mathrm{MIOM}=0)$, those who experienced some kind of mobility (MIOM NOT=0) - either upward or downward - and finally those who left employment to become unemployed, for early retirement or to become a housewife (women only).

The statistics in the table-within the limitations indicated by the confidence intervals - show that for both sexes mobility within the labour market tends to reduce health inequalities. This supports those interpretations which see health as having special relevance within the labour market (Blane, 1999). For men the ratio between the standardised mortality rates of the unskilled working class and the upper middle class seems higher for men who have not been mobile (2.47) than for those who have been mobile, but still remain employed (1.53). For women, the trend is similar, but not statistically significant. 
Table 8

Ratio between excess deaths attributable to social inequalities calculated: (a) for subjects who were hospitalised 1984-86 and downwardly mobile in labour market or left employment; (b) for total population

\begin{tabular}{|c|c|c|c|c|c|}
\hline \multirow[t]{2}{*}{ Population } & \multicolumn{2}{|c|}{$\begin{array}{l}\text { Individuals hospitalised } 1984- \\
86 \text { who were downwardly } \\
\text { mobile between } 1981 \text { and } 1991 \\
\text { or left employment }\end{array}$} & \multicolumn{2}{|c|}{ Total population } & \multirow{2}{*}{$\begin{array}{l}\text { Maximum percentage of deaths } \\
\text { attributable to inequalities due to } \\
\text { processes of occupational mobility } \\
\text { brought about by poor health } \\
b \times 100 / d\end{array}$} \\
\hline & $\begin{array}{l}N \\
\text { (a) }\end{array}$ & $\begin{array}{l}\text { Attributable deaths } \\
\text { (b) }\end{array}$ & $\begin{array}{l}N \\
\text { (c) }\end{array}$ & $\begin{array}{l}\text { Attributable deaths } \\
\text { (d) }\end{array}$ & \\
\hline Men & 1936 & 46.5 & 76,177 & 346.5 & $13.4 \%$ \\
\hline
\end{tabular}

Men aged 25-49 in 1991, mortality follow-up 1991-1999.

The effect on health inequalities of exit from employment runs in the opposite direction, although these results are even more statistically unstable.

\section{To what extent does health-related social mobility contribute to the production of health inequalities?}

Having described the effects of health on occupational mobility, and how these effects are reflected in the way health inequalities are produced, we now need to shift our attention to mobility processes conditioned by health. In particular, we will try to assess the contribution which this particular kind of intra-generational mobility flow makes to social inequalities in health. The empirical evidence which we have here only allows us to consider masculine population and advance hypotheses on the bases of a number of assumptions, which we need to take as plausible. Since we have no information regarding the individual or organisational causes which have led people in poor health towards disadvantaged social categories, we will assume that all individuals who were in poor health during the period of observation (1981-1991) and who experienced downward mobility or left employment did so mainly because of their health. An alternative would have been to take into account also those individuals in poor health who had been occupationally immobile-considering these as having their social mobility limited by poor health. We rejected this possibility however, because we believe it is illegitimate to see occupational immobility as a negative social outcome. It certainly is not negative for those who are in a high social class. But it may not be negative even for members of the working class, since the "costs" of moving to an occupational position different from that they are in may be greater than remaining where they are (Ashford, 1990).

The size of this mobility flow - which we are assuming is that due to poor health - on health inequalities can be estimated by calculating the ratio between the number of deaths attributable to social inequalities in this particular sub-group and the number of deaths attributable to social inequalities in our population as a whole. In both cases, the baseline category which we use as a reference point for calculating excess mortality is the upper middle class, where death rates are significantly lowest for men (see Table 8).

The estimates of the quota of all health inequalities due to downward intra-generational mobility caused by poor health- $13 \%$ for men - is modest but not negligible. As we have argued, the existence of this kind of mobility flow does not place the social nature of health inequalities in doubt, but it does contribute to clarify the nature of such inequalities, alerting us to the presence of discrimination on the basis of health.

\section{Discussion}

Individuals' health influences their chances of occupational mobility and contributes - via the presence of health-conditioned mobility flows - to the overall patterning of social inequalities in health. With regard to mobility within the labour market itself, health has a limited impact, doing no more than limit upward mobility. The effect on exit from employment is much greater. Here, poor health has a substantial effect on the probability of early retirement. The probability of this event is increased by $48 \%$ for men and by $43 \%$ for women (taking occupational immobility as the baseline).

The movements occurring within the labour market itself and in terms of exit from employment (both those of healthy and unhealthy individuals) appear to have effects on the way health inequalities are patterned. Mobility within the labour market seems to have a "diluting" effect on mortality inequalities. This confirms the interpretation provided by Blane (1999), among others. As Blane points out, upward mobility involves the movement of individuals who are healthier than those who they leave behind them (those who, having started off in the same class have remained immobile) but - due to the characteristics of their life trajectoryare less healthy than those they join in their new class. Vice versa downward mobility regards individuals who are less healthy than those they leave behind, but 
individuals who are healthier than those they join. The combination of these two processes means that the epidemiological profile of higher classes deteriorates due to the arrival of recruits from lower classes, while the profile of lower classes improves. This in turn leads to a narrowing of social inequalities in health. The effect of exit from employment seems to be very different, however. Exit seems to exacerbate health inequalitiesa finding which supports the selection hypothesis, albeit indirectly. However, given the low statistical power of the study for this issue, we cam only conclude that this is hypothesis worth following up.

As for the quota of mortality inequalities which is conditioned by health-related intra-generational mobility - the focus of the selection hypothesis - our analysis estimates the size of this at $13 \%$ for men. In all likelihood this is a generous estimate for at least two reasons. Hospital admission is a health indicator which is highly sensitive but not very specific. Using this indicator in fact makes it more likely that a healthy individual will be included among the unhealthy than vice versa (that an unhealthy individual will be missed and included among the healthy). This means that it is likely that we have overestimated the number of unhealthy individuals. The index of occupational mobility, on the other hand is very fine-grained and able to pick up small movements on the occupational scale. The combination of these two indices-hospital admission and MIOM-produces a very generous estimate of unhealthy individuals who have experienced downward mobility. This all suggests that we should consider our estimates as maximum values for the contribution to class inequalities in mortality made by downward intra-generational mobility brought about by poor health. In any case, we have argued that such mobility processes should not be seen as a form of "social Darwinist selection", but rather as a sign — albeit not exclusively - of processes of social discrimination (West, 1991). In addition, it should be stressed that the estimate above only takes into account processes of intra-generational mobility, leaving out of the picture health-related processes of inter-generational social mobility. If we take the latter into consideration, we would have to consider our estimate of the share of health inequalities attributable to processes of mobility affected by health to be a conservative rather than a generous one.

The evidence provided by a longitudinal data base such as the TLS is in many ways appropriate and powerful enough for studying the relationship between health and social mobility. However, the TLS has some limits which should be borne in mind. The first concerns those individuals who leave Turin between one census and another (about 20\%). The TLS has no information on these individuals - which is an important limitation in cases where residential mobility is linked to health events. The second limitation regards the quality of the census information and administrative information which makes up the TLS database: these are records created primarily for administrative purposes rather than for the purposes of research, and hence not always subject to such rigorous controls.

The most important limitation of the study design concerns control over the order in time of the events whose relationship we studied-occupational mobility and decline in health. In particular, employment status and occupation are observed in detail only at the beginning and end of the observation period (in 1986 employment status is recorded but not occupation). This makes it impossible to take into account occupational mobility which occurs on a shorter time-span-which would have helped to control in more detail the order in time of the various events. Another limitation of the research concerns our operational definition of health. As we have pointed out, hospitalisation is a sensitive measure but one which is not very specific.

\section{Acknowledgements}

Roberto Gnavi helped to find the most appropriate procedures for defining health status on the basis of hospital records. Renato Miceli and Teresa Spadea gave helpful advice on the statistical models. To carry out the study we got research founds from Ministero della Salute-Regione Piemonte, Programma speciale ex art. 12 D.Lgs 502/92 for the project "Un sistema informativo, un libro bianco, un modello di monitoraggio per implementare gli obiettivi di equità nella salute e nell'assistenza in Italia", and from ISPEL (Dipartimento Relazioni Esterne e Servizi Comuni di Supporto alle Aree di Ricerca "Casilina e Monteporzio" Unità Funzionale I) for the project "Lavori usuranti: identificazione, misura e valutazione degli effetti correlati” (Ricerca n. 106/95 ( ${ }^{\circ}$ anno), Ricerca 125/97 ( $2^{\circ}$ anno).

\section{Appendix A. Procedure for calculating the metrical index of occupational mobility (MIOM)}

The MIOM is calculated by a procedure which has two phases. First of all, the distance covered by an individual on the scale of occupational desirability during the period considered is calculated via

$\Delta_{1991-1981}=\mathrm{SD}_{1991}-\mathrm{SD}_{1981}$,

where $\Delta_{1991-1981}$ is the size and the direction of the shift on the scale of the social desirability of occupations, $\mathrm{SD}_{1991}$ is the score on this scale of the individual's 1991 
occupation, and $\mathrm{SD}_{1981}$ is the score on the same scale of the 1981 occupation.

According to the value of the $\Delta$ parameter, calculation proceeds as follows. If $\Delta_{1991-1981}$ is nought (i.e the person is occupationally stable or immobile), MIOM equals zero.

If $\Delta_{1991-1981}$ is greater than zero (the individual has been upwardly mobile) the MIOM score is calculated according to

$\mathrm{MIOM}=\frac{\Delta_{1991-1981}}{100-\mathrm{SD}_{1981}} 100$.

Here the index is the percentage reduction in the distance between position on the scale of social desirability occupied in 1981 and the top of the scale.

If the value of $\Delta_{1991-1981}$ is less than zero (the person has been downwardly mobile; the MIOM score is calculated via

$\mathrm{MIOM}=\frac{\Delta_{1991-1981}}{\mathrm{SD}_{1981}-1} 100$

Here the index is the percentage reduction in the distance from the position on the social desirability scale occupied in 1981 and the bottom of the scale.

MIOM can vary from -100 to +100 . MIOM represents occupational mobility taking account not only of the distance covered, but also of the place on the scale of social desirability where the shift started. MIOM is sensitive to occupational mobility which occurs within the confines of a single occupational class, so to short range mobility accompanied by change in the social desirability of the occupations in question. Use of a scale of social desirability of occupations makes it possible in addition to pick up forms of occupational mobility which it is reasonable to think may be conditioned by health or at least by events outside work-for example, the shift from highly skilled working class occupations to unskilled or semi-skilled manual occupations (cf. van de Mheen et al., 1999). MIOM classes these cases as downward mobility, in conformity with social representation of these movements.

\section{References}

Ashford, S. (1990). Upward mobility, status inconsistency, and psychological health. The Journal of Social Psychology, 130, 71-76.

Atkinson, P. (1981). Transition from school to working life. Unpublished memorandum, Sociological Research Unit, University College, Cardiff.

Baldissera, A. (1984). Alle origini della politica della disuguaglianza nell'Italia degli anni '80: La marcia dei quarantamila. Quaderni di Sociologia, 1, 1-78.

Blane, D. (1999). The life course, the social gradient, and health. In M. Marmot, \& R. G. Wilkinson (Eds.), Social determinants of health (pp. 64-80). Oxford: Oxford University Press.

Blane, D., Davey Smith, G., \& Bartley, M. (1993). Social selection: What does it contribute to social class differences in health? Sociology of Health and Illness, 15, 1-15.

Cardano, M., \& Costa, G. (1998). Classi sociali e salute. Le disuguaglianze di mortalità a Torino. Quaderni di Sociologia, 17, 86-121.

Cobalti, A., \& Schizzerotto, A. (1994). La mobilità sociale in Italia. Bologna: Il Mulino.

Costa, G., Cardano, M., \& Demaria, M. (1998). Storie di salute in una grande città. Torino: Città di Torino.

Costa, G., \& Demaria, M. (1988). Un sistema longitudinale di sorveglianza della mortalità secondo le caratteristiche socioeconomiche, come rilevate ai censimenti di popolazione: Descrizione e documentazione del sistema. Epidemiologia e Prevenzione, 36, 37-47.

de Lillo, A., \& Schizzerotto, A. (1985). La valutazione sociale delle occupazioni. Una scala di stratificazione occupazionale per l'Italia contemporanea. Bologna: Il Mulino.

Giddens, A. (1973). The class structure of the advanced societies. London: Hutchinson.

Goldberg, E. M., \& Morrison, S. L. (1963). Schizophrenia and social class. British Journal of Psychiatry, 109, 785-803.

Goldthorpe, J. H. (1980). Social mobility and class structure in modern Britain. Oxford: Claredon Press.

Herzlich, C. (1973). Health and illness: A social psychological analysis. London: Academic Press.

Illsley, R. (1955). Social class selection and class differences in relation to stillbirths and infant deaths. British Medical Journal, 2, 1520-1526.

Kelleher, C., Cooper, J., \& Sadlier, D. (1990). ABO blood group and social class: A prospective study in a regional blood bank. Journal of Epidemiology and Community Health, 44, 59-61.

Lawrence, P. S. (1948). Chronic illness and socioeconomic status. Public Health Reports, 63, 1507-1521.

Marmot, M., \& Wilkinson, R. G. (1999). Social determinants of health. Oxford: Oxford University Press.

Mascie-Taylor, C. G. N. (1990). Biosocal aspects of social class. Oxford: Oxford University Press.

Meadows, S. H. (1961). Social class migration and chronic bronchitis. British Journal of Social Medicine, 15, 171-178.

Morris, J. N., \& Heady, J. A. (1955). Social and biological factors in infant mortality in relation to father's occupation. The Lancet, 269, 499-502.

Parkin, F. (1979). Marxism and class theory: A bourgeois critique. London: Tavistock Publications.

Perrot, G. ST. J., \& Collins, S. D. (1935). Relation of sickness to income and income change in 10 surveyed communities. Health and depression studies no. 1. Method of study and general results for each locality. Public Health Reports, 50, 595-622.

Perrot, G. ST. J., \& Sydenstriker, E. (1955). Causal and selective factors in sickness. American Journal of Sociology, 40, 504-512.

Stern, J. (1983). Social mobility and the interpretation of social class mortality differentials. Journal of Social Policy, 12, 27-49.

Townsend, P., \& Davidson, N. (1982). Inequalities in health: The black report. Harmondsworth: Penguin Books. 
Vågerö, D. (1991). Inequality in health. Some theoretical and empirical problems. Social Science \& Medicine, 32, 367-371.

van de Mheen, H., Stronnks, K., Schrijvers, C. T. M., \& Mackenbach, J. P. (1999). The influence of adult ill health on occupational class mobility and mobility out of employ- ment in The Netherlands. Social Science \& Medicine, 49, 509-518.

West, P. (1991). Rethinking the health selection explanation for health inequalities. Social Science \& Medicine, 32, 373-384.

Wilkinson, R. G. (1986). Class and health: Research and longitudinal data. London: Tavistock. 